\title{
The ultrafine-grained structure, texture and mechanical properties of low carbon steel obtained by various methods of plastic deformation
}

\author{
I.M. Safarov ${ }^{1, \dagger}$, A.V. Korznikov, R.M. Galeyev ${ }^{1}$, S.N. Sergeev ${ }^{1}$, S.V. Gladkovsky², \\ D.I. Dvoynikov², I.Yu. Litovchenko ${ }^{3,4}$ \\ †ilfat@imsp.ru

\begin{abstract}
${ }^{1}$ Institute for Metals Superplasticity Problems RAS, Khalturin St. 39, 450001 Ufa
${ }^{2}$ Institute of Engineering Science of the Urals Branch RAS, Komsomolskaya St. 34, 620049 Yekaterinburg

${ }^{3}$ National Research Tomsk State University, 36 Lenin Ave., 634050, Tomsk
\end{abstract} \\ ${ }^{4}$ Institute of Strength Physics and Materials Science, SB RAS, 2/4 Akademichesky Ave., 634050, Tomsk
}

\begin{abstract}
The paper reports on the investigation of the effect of various methods of plastic deformation on the structure, texture and mechanical properties of low carbon 12GBA steel. It is found that multiple isothermal forging results in formation of equiaxed ultrafine-grained (UFG) structure with a uniform distribution of the second phase, the size of which ranges from 50 to 500 $\mathrm{nm}$. The warm rolling leads to formation of UFG fibrous structure type with presence of carbides sized less than $100 \mathrm{~nm}$. X-ray analysis revealed that both deformation schemes result in formation of two-component (110) [112] and (111) [123] texture. Low carbon steel 12GBA with fibrous UFG structure is characterized by high strength, with satisfactory ductility and toughness values similar to ones in case of the coarse-grained (CG) structure. Equiaxed UFG structure steels possess 2 times higher values of impact strength and 1.5 times increased tensile strength by comparison with the CG structured steel. Internal strains relaxation annealing of UFG fibrous structure leads to second phase coagulation retaining the two component texture and insignificant change of mechanical properties. It was shown that UFG fibrous steels retains its high level due to $1.5-2$ times increase of crack initiation work. Considerable growth of impact strength in equaxed UFG steel takes place due to 7 times increase of crack initiation and propagation work.
\end{abstract}

Keywords: Ultrafine-grained structure, low carbon steel, impact strength.

\section{Ультрамелкозернистая структура, текстура и механические свойства низкоуглеродистой стали, полученной различными методами пластической деформации}

\author{
Сафаров И.М. ${ }^{1, \dagger}$, Корзников А.В. ${ }^{1}$, Галеев Р.М. ${ }^{1}$, Сергеев С.Н. ${ }^{1}$, Гладковский С.В. ${ }^{2}$, \\ Двойников Д.А. ${ }^{2}$, Литовченко И.Ю., ${ }^{3,4}$ \\ †ilfat@imsp.ru
}

${ }^{1}$ Институт проблем сверхпластичности металлов РАН, ул. Степана Халтурина 39, 450001 Уфа

${ }^{2}$ Институт машиноведения УрО РАН, ул. Комсомольская 34, 620049 Екатеринбург

${ }^{3}$ Национальный Исследовательский Томский государственный университет, пр. Ленина 36, 634050 Томск

${ }^{4}$ Институт физики прочности и материаловедения СО РАН, пр. Академический 2/4, 634050 Томск

Проведен анализ влияния разных методов пластической деформации на структуру, текстуру и механические свойства низкоулеродистой стали 12ГБА. Установлено, что после всесторонней изотермической ковки в стали 12ГБА формируется равноосная ультрамелкозернистая (УМЗ) структура с равномерным распределением второй фазы, размер которой варьируется от 50 до 500 нм. После теплой прокатки образуется УМЗ структура волокнистого типа, в которой присутствуют частицы карбидов размером менее 100 нм. В результате обработки по обоим методам деформации в материале формируется двухкомпонентная текстура (110) [112] и (111) [123]. Сталь 12ГБА с волокнистой УМЗ структурой отличается более высокими прочностными свойствами при удовлетворительной пластичности 
и одинаковом уровне ударной вязкости по сравнению с крупнозернистой (КЗ) структурой. В состоянии материала с равноосной УМЗ структурой ударная вязкость повышается в 2 раза, предел прочности в 1,5 раза в сравнении с К3 состоянием. Отжиг для снятия внутренних напряжений образцов стали с волокнистой УМЗ структурой приводит к коагуляции карбидов, к сохранению двухкомпонентной текстуры и незначительному изменению механических свойств. Показано, что в стали с волокнистой УМЗ структурой ударная вязкость сохраняется на высоком уровне за счет возрастания работы распространения трещины в 1,5-2 раза при незначительном снижение работы зарождения трещины. Значительное увеличение ударной вязкости, наблюдаемое в стали с равноосной УМЗ структурой, происходит за счет повышения работы распространения трещины в 7 раз и работы зарождения трещины в 3 раза.

Ключевые слова: ультрамелкозернистая структура, низкоуглеродистая сталь, ударная вязкость.

\section{1. Введение}

Несмотря на то, что в последние годы появляется все больше новых материалов, обладающих несравнимо высоким комплексом свойств [1,2], низкоуглеродистые стали остаются одним из самых широко применяемых материалов в разных отраслях промышленности в связи со своей низкой стоимостью и высокими технологическими свойствами. Следствием этого является то, что до сих пор не потерян интерес к этому классу сталей как к объекту широкого круга исследований [3-9], направленных на повышение их прочностных свойств и хладостойкости. А повышение комплекса механических свойств материалов путем формирования ультрамелкозернистой структуры рождает новые перспективы для низкоуглеродистых сталей и способно еще больше расширить их область применения [10]. В этом направлении уже есть немало исследовательских работ, например, в [6,9-12] показано, что измельчение структуры в объемных заготовках из низкоуглеродистых сталей приводит к существенному повышению прочностных свойств при сохранении удовлетворительной пластичности. Однако остается актуальным вопрос о выборе из существующих методов получения УМЗ структуры $[13,14]$ наиболее эффективных как с экономической, так и с технологической стороны. Для решения такой задачи требуется проведение сравнительного анализа механических свойств сталей с УМЗ структурой, полученной различными способами деформационной обработки, который позволит определить наиболее оптимальные пути получения стальных заготовок с требуемым комплексом механических свойств.

Исходя из этого, авторами была поставлена задача проанализировать ультрамелкозернистые состояния, полученные в низкоуглеродистой стали различными методами пластической деформации, с целью выявления характерных закономерностей влияния типа и морфологии структуры на прочность и ударную вязкости стали.

\section{2. Материал и методики эксперимента}

В качестве материала исследования была выбрана низкоуглеродистая сталь 12ГБА (Fe-1,2\% Mn-0,35\% $\mathrm{Cu}-$ $0,25 \% \mathrm{Si}-0,11 \% \mathrm{C}-0,05 \% \mathrm{Nb}-0,012 \% \mathrm{P}-0,005 \% \mathrm{~S})$, используемая для производства труб.

Структура образцов низкоуглеродистой стали 12ГБА перед деформационно-термической обработкой состояла из зерен феррита со средним размером $25 \pm 7$ мкм и 13,4 об.\% перлита в виде колоний. Исходная ферритно- перлитная структура в материале была получена горячей ковкой в интервале температур $1100-950^{\circ} \mathrm{C}$ и последующим охлаждением с печью.

Деформационную обработку стальных заготовок выполняли двумя методами - путем всесторонней изотермической ковки и теплой прокатки. Всестороннюю изотермическую ковку проводили на гидравлическом прессе модели ПА 2638 в интервале скоростей деформации $10^{-3}-10^{-2} \mathrm{c}^{-1}$ при понижении температуры этапов ковки с 650 до $450^{\circ} \mathrm{C}$, через каждые $50^{\circ} \mathrm{C}$. На каждом этапе проводилось три осадки во взаимно перпендикулярных направлениях на 40-50\% от высоты образца при температуре деформации. Суммарная истинная степень деформации на каждом этапе при одной температуре составляла $\varepsilon=2,06$. Накопленная истинная степень деформации составила $\varepsilon=10,3$ [11]. Теплую прокатку проводили на стане МКУ-280 с 4-х валковым калибром за несколько проходов с исходного сечения заготовки 20 мм $\times 20$ мм до конечного сечения 8 мм $\times 8$ мм при ступенчатом понижении температуры нагрева заготовки с 750 до $550^{\circ} \mathrm{C}$. Перед каждым проходом выполняли подогрев заготовки до температуры прокатки. Накопленная истинная степень деформации составила $\varepsilon=2,7$ [10].

Структурный анализ стали после деформационнотермической обработки проводился методами просвечивающей электронной микроскопии (ПЭМ) на электронном микроскопе «JEOL JEM-2000ЕХ», растровой электронной микроскопии на микроскопе «Tescan Mira 3LMH».

Рентгеноструктурный анализ проводился на дифрактометре Shimadzu XRD-6000 (Томский материаловедческий центр коллективного пользования «ТГУ») с использованием $\mathrm{Cu}$ K $\alpha$ излучения в геометрии Брегга-Брентано с фокусирующим монохроматором на вторичном пучке.

Механические испытания на растяжение плоских образцов с размером рабочей части $1,5 \times 1 \times 11$ мм проводили на универсальной испытательной машине «INSTRON-1185» при комнатной температуре с начальной скоростью деформации 10 $0^{-3} \mathrm{c}^{-1}$ по ГОСТ 1497-84. Значения механических свойств усреднялись по результатам испытаний не менее трех идентичных образцов, при этом разброс данных не превышал 10\%.

Испытания на ударный изгиб образцов нестандартного размера 7 мм $\times 7$ мм $\times 55$ мм с V-образным надрезом глубиной 1,5 мм проводили на инструментированном маятниковом копре «Tinius Olsen IT542M» при температуре от $20^{\circ} \mathrm{C}$, входящим в состав оборудования ЦПК «Пластометрия» ИМАШ УрО РАН». Процедура ударных испытаний регламентировалась требованиями ГОСТ 9454-78. 


\section{3. Результаты исследований и их обсуждение}

Рассмотрим влияние метода теплой прокатки на структуру низкоуглеродистой стали 12ГБА. На рис. 1 а представлена микроструктура стали в сечении вдоль направления прокатки. Видно, что структура состоит из сильно вытянутых зерен и субзерен. Дифракционный контраст вдоль волокон резко меняется от светлого до темного. Это обусловлено наличием в теле волокон неразориентированной дислокационной субструктуры. Изменение плотности дислокаций от участка к участку в теле волокон создает достаточно высокие внутренние напряжения и приводит к изгибу кристаллической решетки. Об этом также свидетельствуют изгибные контура экстинкции на изображении, расположенные поперек волокон. Ширина волокон варьируется от 0,1 до 0,8 нм, среднее поперечное расстояние между границами равно 0,4 мкм (поперечное расстояние определялось методом пересечения границ зерен в интересуемом направление). Цементит, который в исходном состоянии, т. е. после горячей деформации, имел пластинчатую форму, после прокатки трансформировался в мелкие дисперсные частицы, расположенные, как в теле зерен/ субзерен, так и по их границам. Размер частиц второй фазы после теплой прокатки не превышал 200 нм.

Проведение часового отжига при температуре $550^{\circ} \mathrm{C}$ образцов после прокатки (рис. 1 б) привело к незначительному возрастанию среднего размера зерен/субзерен с 0,4 мкм до 0,5 мкм. При этом наблюдается коагуляция второй фазы, и размер некоторых частиц достигает 1 мкм. В целом структура сохраняет свою вытянутость и становится более равновесной, что определяется протеканием процессов статического возврата и рекристаллизации.

Учитывая размер зерен в исходном до прокатки состоянии и размер поперечного сечения волокон после прокатки, можно предположить, что в процессе деформации прокаткой в силу неизотермических условий и высоких скоростей деформации динамическая рекристаллизации была подавлена и трансформация струк-

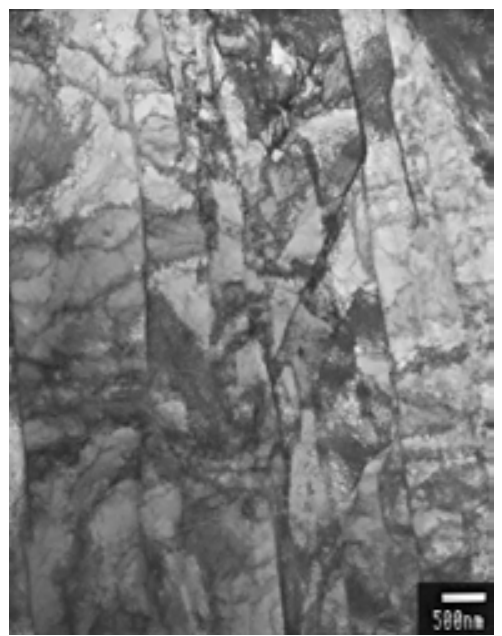

a

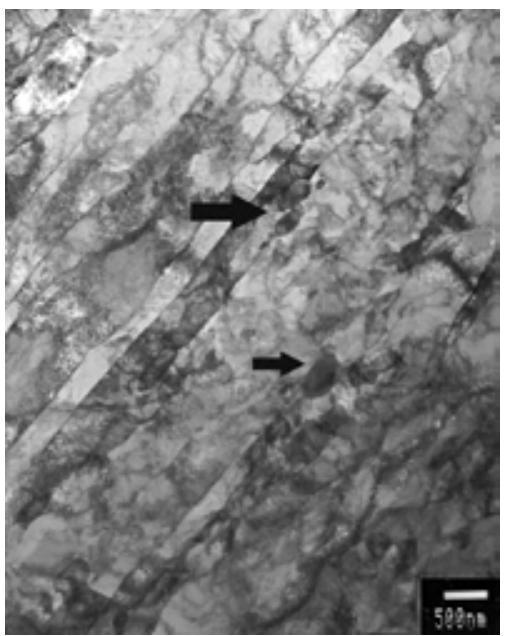

b

Pис. 1. Микроструктура стали 12ГБА в продольном сечении: после теплой прокатки (а), после теплой прокатки и последующего отжига при $550^{\circ} \mathrm{C}(\mathrm{b})$.

Fig. 1. Microstructure of $12 \mathrm{GBA}$ steel in longitudinal section: subjected to warm rolling (a), subjected to warm rolling and annealing (b).

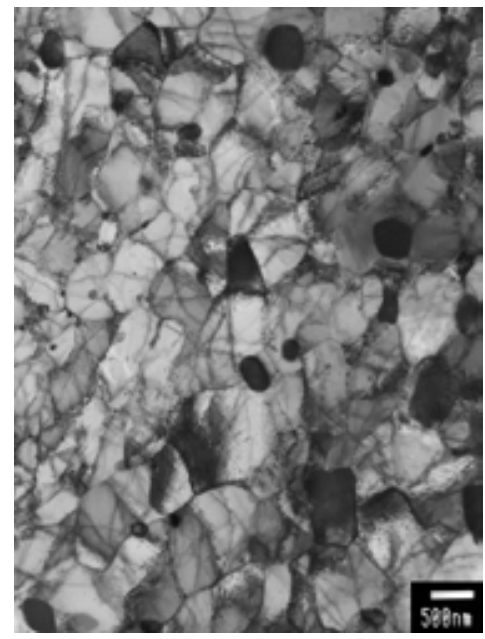

a

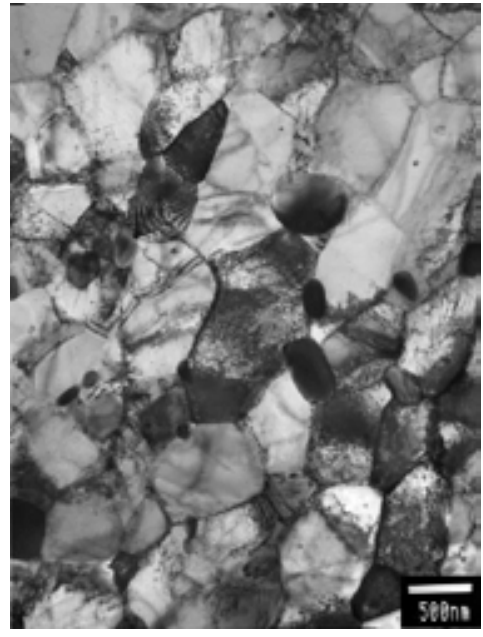

$\mathrm{b}$

Pис. 2. Микроструктура стали 12ГБА после ковки (a), ковки и последующего отжига при $550^{\circ} \mathrm{C}(\mathrm{b})$.

Fig. 2. Microstructure of $12 \mathrm{GBA}$ steel: subjected to forging (a), subjected to forging and annealing (b). 
туры шла в большей степени за счет изменения формы зерен, т. е. их вытягивания вдоль направления прокатки.

Всесторонняя изотермическая ковка также привела к значительному изменению исходной структуры, но при этом сформировалась структура более равноосного вида со средним размером зерен/субзерен 0,5 мкм. Плотность дислокаций достаточно сильно различается от зерна к зерну, в зависимости от чего дислокационная структура в теле зерен/субзерен изменяется от равномерно-хаотичного распределения до ячеисто-сетчатых построений. Такая структура типична для процессов динамической рекристаллизации, когда идет зарождение и рост новых зерен, свободных от дефектов и одновременно накопление избыточной плотности дислокации в уже рекристаллизованных зернах. Пластинчатый цементит трансформируется в частицы сферической формы, как и после прокатки, но размер частиц второй фазы варьируется от 50 до 500 нм, что объясняется меньшей скоростью деформации и, соответственно, большими выдержками при температуре ковки.

После дополнительного отжига при $550^{\circ} \mathrm{C}$ кованых образцов в их структуре наблюдается небольшое увеличение среднего размера зерна/субзерна до 0,6 мкм, размер карбидов при этом сохраняется и не превышает 500 нм.

Как показал текстурный анализ образцов после прокатки и ковки, а также образцов после дополнительных отжигов (рис. 3), в исходном состоянии после горячей деформации в стали 12ГБА формируется слабая текстура (100) [001]. После теплой прокатки формируется более сильная текстура, в которой присутствуют компоненты (110) [112] и (111) [123]. Образование многокомпонентной текстуры обусловлено воздействием при данной схеме прокатки одновременного обжатия образцов в двух взаимно перпендикулярных направлениях. В кованых образцах стали 12ГБА текстура подобна текстуре после прокатки, но с менее выраженными компонентами (110) [112] и (111) [123]. Формирование текстуры в образцах, полученных ковкой, связано с тем, что на последнем этапе всесторонней ковки производилась операция протяжки, то есть осадка образца велась только в двух взаимно перпендикулярных направлениях с вытя-
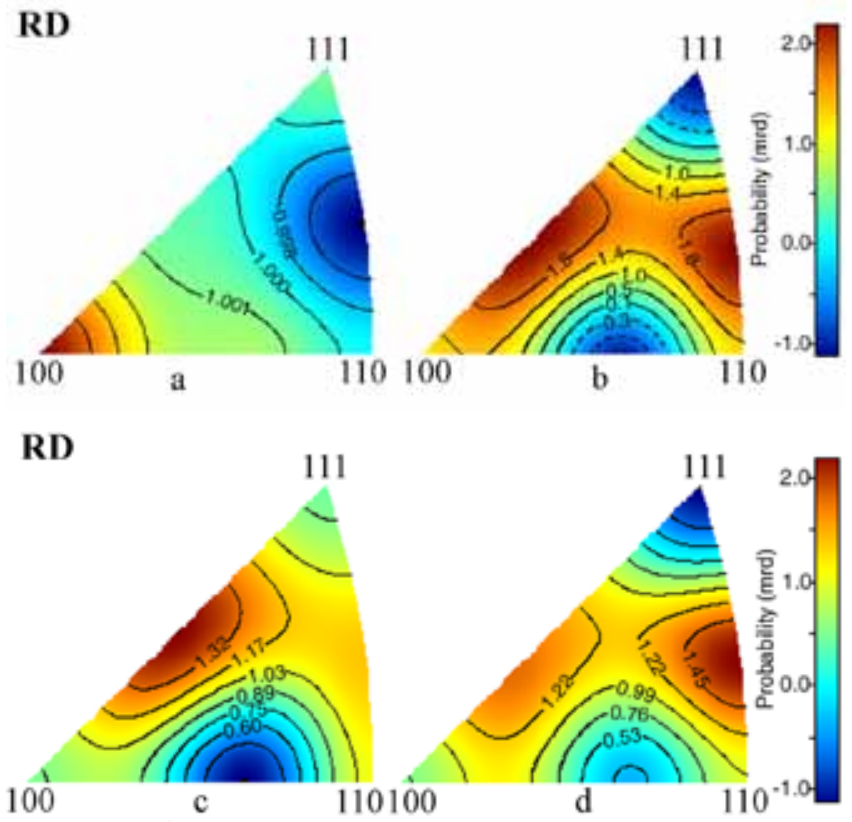

Pис. 3. (Color online) Обратные полюсные фигуры в образцах стали 12ГБА после горячей деформации (a), теплой прокатки (b), теплой прокатки и последующего отжига при $550^{\circ} \mathrm{C}$ (c), ковки (d).

Fig. 3. (Color online) Inverse pole figures in the steel samples 12GBA: subjected to hot deformation (a), subjected to warm rolling (b), subjected to warm rolling and annealing (c), subjected to forging (d).

гиванием образца в третьем направлении. Данная операция проводилась с целью получения соответствующих размеров заготовки для последующей вырезки образцов для ударных испытаний.

После отжига деформированных ковкой и прокаткой образцов при $550^{\circ} \mathrm{C}$ происходит частичное размытие сформировавшийся текстуры, связанное с рекристаллизационными процессами.

Механические свойства коррелируют со структурными параметрами полученных состояний стали (табл. 1). Так, после формирования волокнистой УМЗ структуры с мелкодисперсными карбидами при теплой

Табл. 1. Механические свойства стали 12ГБА.

Table 1. Mechanical properties of the 12GBA steel.

\begin{tabular}{|c|c|c|c|c|}
\hline $\begin{array}{c}\text { Режим обработки } \\
\text { Treatment conditions }\end{array}$ & $\begin{array}{l}\sigma_{0.2}, \mathrm{MПа} \\
\sigma_{0.2}, \mathrm{MPa}\end{array}$ & $\begin{array}{l}\sigma_{\text {s}}, \mathrm{M \Pi а} \\
\sigma_{u}, \mathrm{MPa}\end{array}$ & $\delta, \%$ & $\psi, \%$ \\
\hline $\begin{array}{c}\text { После горячей деформации } \\
\text { Hot deformation }\end{array}$ & 330 & 510 & 20 & 75 \\
\hline $\begin{array}{l}\text { После прокатки } \\
\text { Rolled }\end{array}$ & 797 & 900 & 18 & 83 \\
\hline $\begin{array}{c}\text { После прокатки и отжига при } 550^{\circ} \mathrm{C} \\
\text { Rolled + annealing } 550^{\circ} \mathrm{C}\end{array}$ & 650 & 699 & 23 & 86 \\
\hline $\begin{array}{l}\text { После ковки } \\
\text { Forging }\end{array}$ & 600 & 730 & 14 & 80 \\
\hline $\begin{array}{c}\text { После ковки и отжига при } 550^{\circ} \mathrm{C} \\
\text { Forging+ annealing } 550^{\circ} \mathrm{C}\end{array}$ & 570 & 690 & 17 & 83 \\
\hline
\end{tabular}


прокатке предел прочности стали 12ГБА повышается почти на $100 \%$, а предел текучести возрастает более чем в 2 раза по сравнению с исходным горячедеформированным состоянием. Пластичность при этом сохраняется на достаточно высоком уровне. Формирование после ковки равноосной УМЗ структуры с большим средним размером зерна и менее дисперсной карбидной фазой приводит к повышению предела прочности всего на 50\%, при этом происходит снижение относительного удлинения до разрыва $(\delta)$ до $14 \%$.

Дополнительный отжиг при $550^{\circ} \mathrm{C}$ в образцах стали после теплой прокатки привел снижению предела текучести на 90 МПа и повышению $\delta$ на $5 \%$, что обусловлено изменением структуры, описанным выше. В кованых образцах стали 12ГБА после отжига прочностные свойства снижаются незначительно, а пластичность возрастает до уровня прокатанных образцов. Полученные результаты механических испытаний подтверждают, что в образцах после ковки и последующего отжига превалируют процессы возврата без существенных структурных изменений.

Проведенные ударные испытания на изгиб при комнатной температуре (табл. 2) показали преимущество в ударной вязкости УМЗ структуры обоих типов по сравнению с ферритно-перлитной структурой. При этом самые высокие значения ударной вязкости имеют образцы после ковки. Прокатанные образцы показывают повышение уровня ударной вязкости на $12 \%$ по сравнению с исходным состоянием, а после отжига KCV прокатанных образцов повышается еще на $36 \%$. После теплой прокатки температура вязко-хрупкого перехода сместилась до $-80^{\circ} \mathrm{C}$ по сравнению с исходным состоянием, в котором составляла $-30^{\circ} \mathrm{C}$. Проведение дополнительного отжига прокатанных образцов стали привело к снижению температуры вязко-хрупкого перехода ниже $-80^{\circ} \mathrm{C}$. В образцах после всесторонней изотермической ковки значение температуры вязко-хрупкого перехода также лежало ниже $-80^{\circ} \mathrm{C}$.

Механические свойства кованых образцов стали 12ГБА после отжига практически не изменяются, поэтому испытания отожженных образцов на ударный изгиб не проводили.

Программное обеспечение установки, на которой проводились ударные испытания, позволяет записывать диаграммы нагружения и определять по ним вклады работ зарождения и распространения трещины в общую работу разрушения. Анализ полученных данных по методике [15], представленных в таблице 2, показал, что эффект повышения ударной вязкости в УМЗ стали в основном обусловлен значительным возрастанием работы распространения трещины. Это объясняется тем, что намного большая протяженность границ зерен в УМЗ материале создает больше барьеров на пути распространения трещины.

Работа зарождения трещины в меньшей мере влияет на ударную вязкость полученных состояний стали 12ГБА. Так, в состоянии после прокатки значение работы зарождения трещины даже снижается по сравнению с исходной структурой, но за счет более развитой поверхности границ зерен существенно возрастает работа распространения трещины, в результате общая работа разрушения становится выше.

Проведение отжига деформированных образцов стали после прокатки приводит к повышению значения работы зарождения и работы распространения трещины за счет снижения уровня внутренних напряжений и перехода зеренно-субзеренной структуры в более равновесное состояние.

В состоянии после ковки увеличение ударной вязкости вызвано возрастанием значения $A_{3}$ трещины в 3 раза и значения $A_{p}$ трещины в 7 раз. По-видимому, такому резкому повышению ударной вязкости благоприятствует несколько факторов, таких как формирование равноосной УМЗ структуры, более слабая текстура и более равномерное распределение частиц карбидов в результате фрагментации, сфероидизации и коагуляции карбидных пластин.

Таким образом, формирование УМЗ структуры различного типа в низкоуглеродистой стали 12ГБА способствует повышению прочностных свойств и ударной вязкости при комнатной температуре. Отметим, что формирование волокнистой УМЗ структуры по сравнению с равноосной УМЗ структуры при прочих равных прочностных свойствах имеет преимущество в пластических свойствах. Но при этом равноосная УМЗ структура позволяет достичь двукратного повышения ударной вязкости, что весьма важно для конструкционной прочности сталей.

Табл. 2. Результаты испытаний на ударный изгиб образцов стали 12ГБА.

Table 2. The results on the impact bending test steel samples 12GBA.

\begin{tabular}{|c|c|c|c|c|}
\hline $\begin{array}{c}\text { Режим обработки } \\
\text { Treatment conditions }\end{array}$ & $\begin{array}{c}\mathrm{KCV}, \mathrm{MДж} / \mathrm{M}^{2} \\
\mathrm{KCV}, \mathrm{MJ} / \mathrm{m}^{2}\end{array}$ & $\begin{array}{c}A, \text { Дж } \\
A, \mathrm{~J}\end{array}$ & $\begin{array}{c}A_{3}, \text { Дж } \\
A_{i}, \mathrm{~J}\end{array}$ & $\begin{array}{c}A_{p}, \text { Дж } \\
A_{p}, \mathrm{~J}\end{array}$ \\
\hline $\begin{array}{l}\text { После горячей деформации } \\
\text { Hot deformation }\end{array}$ & 1,07 & 33,2 & 11,7 & 21,5 \\
\hline $\begin{array}{l}\text { После прокатки } \\
\text { Rolled }\end{array}$ & 1,20 & 37 & 5 & 32 \\
\hline $\begin{array}{c}\text { После прокатки и отжига при } 550^{\circ} \mathrm{C} \\
\text { Rolled + annealing } 550^{\circ} \mathrm{C}\end{array}$ & 1,59 & 50 & 10 & 40 \\
\hline $\begin{array}{l}\text { После ковки } \\
\text { Forging }\end{array}$ & 2,36 & 182,6 & 34 & 148,6 \\
\hline
\end{tabular}


Видоизменяя морфологические параметры структурных элементов посредством деформационной обработки, можно оптимизировать весь комплекс механических свойств материалов, то есть добиться одновременного повышения прочности, пластичности и ударной вязкости.

\section{4. Выводы}

1. В зависимости от метода пластической деформации, то есть теплой прокатки или всесторонней изотермической ковки, в низкоуглеродистой стали 12ГБА формируется, соответственно, волокнистая или равноосная УМЗ структура.

2. Низкоуглеродистая сталь 12ГБА с волокнистой и равноосной УМЗ структурой при комнатной температуре отличается более высокой прочностью, ударной вязкостью, удовлетворительным уровнем пластичности по сравнению со сталью с исходной КЗ структурой.

3. В низкоуглеродистой стали 12ГБА при обеих схемах деформации формируется двухкомпонентная текстура (110) [112] и (111) [123], которая после дополнительного отжига частично размывается.

4. Основной вклад в повышение ударной вязкости в стали с УМЗ структурой вносится за счет увеличения работы распространения трещины, что обусловлено более развитой по сравнению с исходным КЗ состоянием поверхностью границ зерен, препятствующих распространению трещины.

\section{Литература/References}

1. S.V. Gladkovskii, T.A. Trunina, E.A. Kokovikhin, S.V. Smirnova, I.S. Kamantsev, A.V. Gorbunov, Metal Science and Heat Treatment. (in Russian) [C.В. Гладковский, Т.А. Трутина, Е.А. Коковихин, С.В. Смирнова, И.С. Каманцев, А.В. Горбунов. Металловедение и термическая обработка металлов. 1(691), 3-7 (2013)]

2. I.I. Musabirov, R.R. Mulyukov, I.Z. Sharipov. Russian Physics Journal 58 (6), 5-9 (2015) (in Russian) [И.И. Мусабиров, Р.Р. Мулюков, И.З. Шарипов. Известия высших учебных заведений. Физика. 58 (6), 5-9 (2015)]

3. V.M. Farber, O.V.Selivanova, A.B. Arabey, O.N. Polukhina, A.S. Mamatnazarov. Metal Science and Heat Treatment. 8 (710), 53-55 (2014) (in Russian) [В.М. Фарбер, О.В. Селиванова, А.Б. Арабей, О.Н. Полухина, А.С. Маматназаров. Металловедение и термическая обработка металлов. 8(710), 53-55 (2014)]

4. V.M. Schastlivtsev, T.I. Tabatchikova, I.L. Yakovleva, S.Y. Del'gado Reina, S.A. Golosienko, U.A. Pazilova, E.I. Khlusova. Phys. Met. Metallogr. 116(2), 199-209 (2015). (in Russian) [В.М. Счастливцев, Т.И. Табатчикова, И.Л. Яковлева, С.Ю. Дельгадо Рейна, С.А. Голосиенко, У.А. Позилова, Е.И. Хлусова. Физика металлов и металловедение. 116(2), 199-209 (2015).] DOI: 10.7868/ S0015323015020102.
5. M.A. Smirnov, I. Yu. Pyshmintsev, O.V. Varnak, A.N. Maltseva. Russian metallurgy (Metally). 8, 9-15 (2014). (in Russian) [М.А. Смирнов, И.Ю. Пышминцев, О.В. Варнак, А.Н. Мальцева. Деформация и разрушение материалов. 8, 9-15 (2014).]

6. G.G. Maier, E.G. Astafurova, E.V. Naydenkin, H.J. Maier, G.I. Raab, P.D. Odessky, S.V. Dobatkin. Mater. Sci. and Eng.:A. 581, 104(2015). DOI: 10.1016/j.msea.2013.05.075.

7. E.G. Astafurova, G.G. Maier, V.S. Koshovkina, E.V. Melnikov, E.V. Naydenkin, A. Smirnov, V.A. Bataev, P.D. Odessky, S.V. Dobatkin. Letters on Materials 5 (4), 432 (2015).

8. R.Z. Valiev, A.V. Ganeev, G.V. Klevtsov, N.A. Klevtsova, V.M. Kushnarenko. Steel in Translation. 44 (6), 418 (2014).

9. R.Z. Valiev, G.V. Klevtsov, N.A. Klevtsova, M.V. Fesenyuk, M.R. Kashapov, A.G. Raab, M.V. Karavaeva, A.V. Ganeev. Russian metallurgy (Metally). 1, 21 (2013). (in Russian) [Р.3. Валиев, Г.В. Клевцов, Н.А. Клевцова, М.В. Фесенюк, М.Р. Кашапов, А.Г. Рааб, М.В. Караваева, А.В. Ганеев. Деформация и разрушение материалов. 1, 21 (2013).]

10. S.N. Sergeev, I.M. Safarov, A.V. Korznikov, R.M. Galeyev, S.V. Gladkovskii, D.I. Dvoynikov. Letters on Materials. 5(1), 48-51 (2015). (in Russian) [C.H. Сергеев, И.М. Сафаров, А.В. Корзников, Р.М. Галеев, С.В. Гладковский, Д.А. Двойников. Письма о материалах, 5(1), 48-51 (2015).]

11. I.M. Safarov, A.V. Korznikov, R.M. Galeyev, S.N. Sergeev, S.V. Gladkovskii, I.Yu. Doklady Physics. 115(3), 315-323 (2016). (in Russian) [И.М. Сафаров, А.В. Корзников, P.М. Галеев, С.Н. Сергеев, С.В. Гладковский, И.Ю. Пышминцев. Доклады Академии Наук. 466(3), 289292 (2016).] DOI: 10.7868/S0869565216030117

12. I.M. Safarov, A.V. Korznikov, R.M. Galeyev, S.N. Sergeev, S.V. Gladkovskii, E.M. Borodin. I.Yu. Pyshmintsev. Phys. Met. Metallogr. 115(3), 315-323 (2014). (in Russian) [И.M. Сафаров, А.В. Корзников, Р.М. Галеев, С.Н. Сергеев, С.В. Гладковский, Е.М. Бородин, И.Ю. Пышминцев. Физика металлов и металловедение. 115(3), 315-323 (2014).] DOI: 10.7868/S0015323014030103.

13. F. Utyashev. G.I. Raab. The deformation methods of obtaining and processing of ultrafine-grained and nanostructured materials. Ufa. (2013) 376 p. (in Russian) [Ф.3. Утяшев, Г.И. Рааб. Деформационные методы получения и обработки ультрамелкозернистых и наноструктурных материалов // Уфа: Гилем. НИК Башк. энцикл. 2013. 376 с.]

14. A.A. Nazarov, R.R. Mulyukov. Nanostructured Materials. Chapter 22. In: Handbook of Nanoscience, Engineering, and Technology, Ed. Goddard W., Brenner D., Lyshevski S., Iafrate G., Boca Raton, London, New York, Washington, D.C.: CRC Press. 2002.

15. L.R. Botvina. Destruction: kinetics, mechanisms, general laws. M: Science, (2008) 334 p. (in Russian) [Л.P. Ботвина. Разрушение: Кинетика, механизмы, общие закономерности. М: Наука, 2008. 334 с.] 